symptoms temporarily, while in some instances their effects are apparently lasting.

In conclusion, it may be urged that the injections are too simple-too insignificant-to be of service in the treatment of phthisis, but any one who takes a broad and impartial view of the whole field of phthisiology must feel that the essential method of alleviating phthisis does not and can not consist of a complicated mechanism. This must be true, or in what other manner can we account for the so-called spontaneous cures-the healed phthisical lesions found in many lungs on the postmortem table or in the dissecting-room, in which death did not result from phthisis? The cure in these instances-for cure it undoubtedly is-was simple; was not brought about by the administration of formidable doses of refined remedies, or was not the outcome of special treatment administered through complicated machinery and expensive paraphernalia; but in all probability it was the sequence of some change of habit, or was effected by calling into play some new influence of a terrestrial; social, psychic, or moral character, which diverted the abnormal movement into a channel of health so rradually and so imperceptibly as to elude, perhaps, even the consciousness of the patient. By this I do not wish to convey the idea that the cure of the disease is always readily and easily accomplished by art, but that this is possible in many instances does not admit of doubt; and if we are not able to do as well or better than nature, we ought to follow the example of the immortal Sims, who, in his despondency after the loss of his two first patients, tore his shingle off the window, threw it into the well, and vacated the town.

\section{'TUBERCULOSIS OF THE LUNGS TREATED BY COMPRESSION WITH NITROGEN AFTER THE METHOD OF MURPHY.}

WITU FLRTHER REMARKS ON THE RATIONALE OF THE PROCEDURE AND A RECORD OF EXPERIMENTS ON DOGS.*

\section{A. F. LEMKE, M.1). CHIS:Ago.}

More than two years have elapsed since the idea of artificially compressing a tuberculous lung was put into extensive practice. During this time the pathology of compressed tuberculous lungs has been carefully studied, the literature has been more thoroughly searched for the expressions of clinicians and pathologists as to the value of compression of tuberculous lungs, such as results from pleurisy with effusion, either serous or purulent, and a series of experiments on dogs has been made to determine the effect compression has upon healthy Iung tissue and to observe what changes, if any, are to be found in the pleura as the result of the prolonged contact with these membranes of agents used for compression, such as nitrogen and normal-salt solution. At the Columbus meeting of the AMERICAN MEDICAL AssoCIATION I reported in detail 53 cases of pulmonary tuberculosis, in its various stages, that had been treated by means of intrapleural injections of nitrogen. Many other cases were reported more briefly. Since that time about 100 new cases have been treated. Time and space will not permit a careful record of these cases, and I shall direct your attention to those cases in particular that illustrate some of the points I wish to emphasize.

* Presented in a Symposium on Tuberculosis, to the Section on Practice of Medicine, at the Fifty-first Annual Meeting of the American Medical Association, held at Atlantic City, N. J., June i-8, 1900 .
Furthermore the results are of little practical value at this time.

It will not be a waste of time to refer again to the overwhelming evidence, clinical and pathological, bearing on this point that is to be found in medical literature. I will direct your attention to the paragraph which appears in Stoke's work on "Diseases of the Chest," published in 1844, in which he says: "In many cases, where the disease-speaking of pulmonary tuberculosis complicated by pneumothorax-becomes chronic. we may observe a singular suspension of the usual symptoms of phthisis; the sweats cease; the pulse I have known in some cases to become quiet and the patient may gain flesh and strength to a surprising degree." Blakiston, in his work published in 1848, in the chapter on the termination of phthisis, cites several cases of recovery that bear on this question. In the works of Jaccoud, Williams, Cornet, Fowler and Godlee, Paget and a number of older as well as more recent writers,

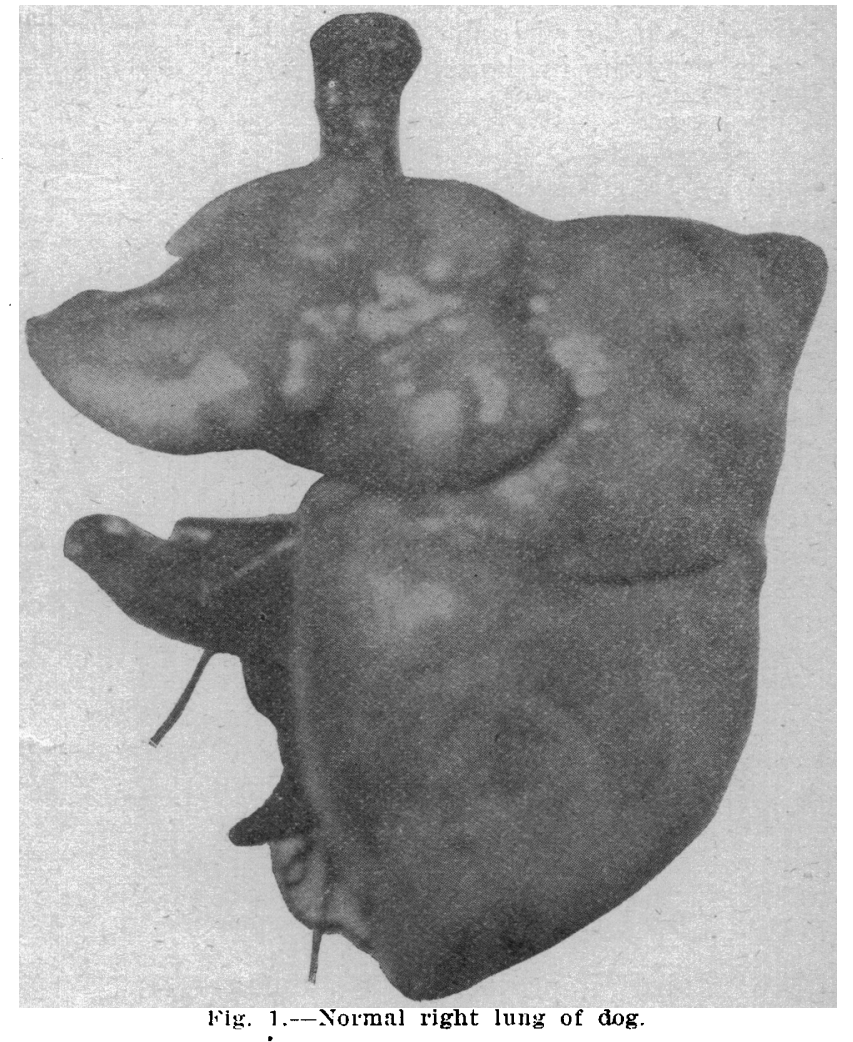

may be found cases of pulmonary tuberculosis either very much improved or cured as the result of some such complication as pneumothorax or pleurisy with effusion which kept up for some time a more or less thorough compression of the organ.

You are all familiar with the very interesting chapter in the history of medicine that deals with the development of the operation of paracentesis of the thorax for pleurisies with effusion. You know how often this operation has been urged only to be condemned sooner or later by some one driven to do so by adverse experiences. Almost a constant warfare was kept up until Trousseau pointed out the indications for the operation that you are all familiar with. Since Trousseau's time some changes have been made in the indications, and I may say, without fear of contradiction, that at the present time, knowing, as we do from the experiments of Eichhorst and others, that more than one-half of the cases of pleurisy with effusion are tuberculous, the disease being secondary very frequently to tuberculosis of 
the lung, the tendency is to allow the fluid to remain, unless special indications arise to make its removal imperative. This question of the etiology of the ordinary pleurisy with effusion and the indications for the removal of the fluid has an important bearing on the question under discussion, but it is too complicated to be carefully considered at this time. I may mention, as briefly as possible, a case of pulmonary tuberculosis, complicated with pleurisy with effusion, that occurred in the practice of Dr. Murphy eight years ago, and that was largely responsible, I believe, for the ideas that led to his original experiment of injecting nitrogen into the pleural cavity to compress tuberculous lungs. The case was that of a middle-aged woman from LaSalle, Ill., who consulted him for pulmonary disease, which proved to be tuberculosis. Physical signs were detected over the entire left upper lobe and tubercle bacilli were demonstrated in the sputum. The woman was very much emaciated, the pulmonary disease rather widespread, and an unfavorable prognosis was made. Within a few weeks of her visit she developed left pleurisy with effusion, resulting in thorough compression of the lung,

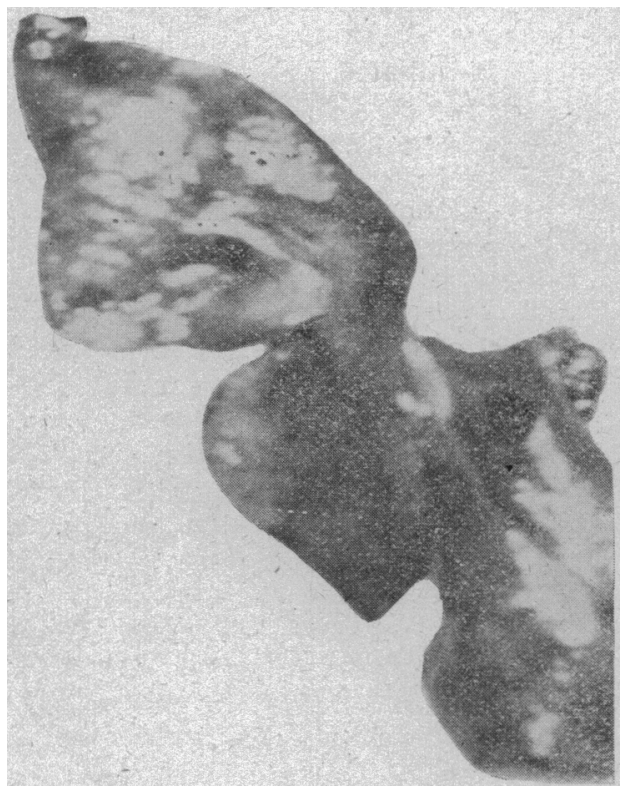

Fig. 2.-Compressed left lung of dog.

with a gradual improvement of pulmonary symptoms and finally a complete recovery from both pulmonary and pleural diseases. I had an opportunity of examining this patient two and one-half years ago, and the only evidence remaining of an old pulmonary tuberculosis was harsh, rough breathing over the left upper lobe. Symptomatically, she was perfectly well.

Last year Pinquet, of France, emphasized the desirability of maintaining pulmonary compression in pleurisy with effusion secondary to tuberculosis of the lung, and reported a case of tuberculization of the lung following thoracocentesis.

It has been urged that, if pleurisy with effusion is frequently, if not usually, secondary to tuberculosis of the lung, and even though many cases of pulmonary tuberculosis improve, or apparently recover, as a result of such compression, this change, it would seem, is only temporary, as is evidenced by the subsequent development of symptoms of active pulmonary disease. In this country we have the valuable statistics of Bowditch, who investigated the cases of pleurisy that occurred in his father's practice, and those of Osler, who reported, in his Shattuck lectures in 1893 , that of 56 cases of pleu- risy admitted to Johns Hopkins Hospital during the four years prior to his report, only four cases were known to have developed tuberculosis of the lungs subsequently. Späth" in an article, "Ueber Die Beziehungen der Lungencompression zur Lungentuberculose," cites a very interesting case to show the good effect of pleural effusion in preventing the dissemination of the infection into the compressed portion of the lung.

Observations on the favorable effect of compression of tuberculous lungs have not been limited to clinicians. Rokitansky made the observation that in spinal curvatures or other distortions of the thorax resulting in more or less compression of one or the other lung, tuberculosis of the organ so affected never occurred. In speaking of the effects of compression by pleural effusion, he said: "We may here further adduce the fact that the compression exercised by pleural effusion and a consecutive abiding increase of compactness of one lung as denoted by a sinking in of the thorax, in like manner extinguishes the tendency to tuberculosis."

It is a common observation in the dead-house that lungs that have been for some time tuberculous usually

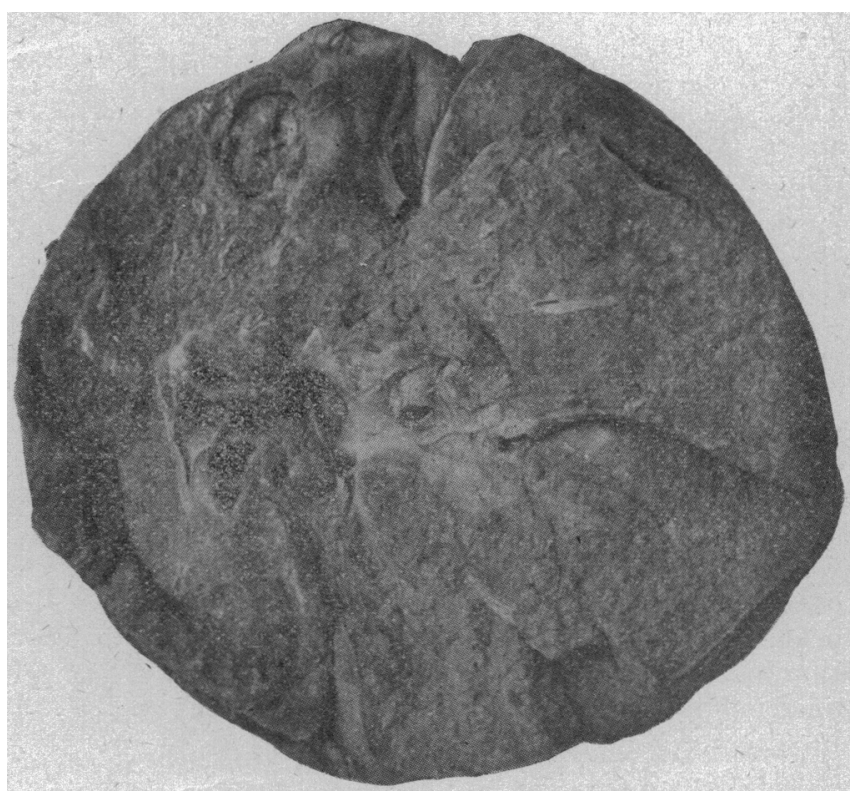

Figure $3 a$

show considerable fibrosis in the neighborhood of the affected areas, and this is particularly true of diseased lungs that have been subjected to pressure such as pertains to empyema, in pleurisy with serous effusion, pneumothorax, etc. Knowing as we do that tuber. culosis of the lung heals, and we know there is always a tendency in that direction, it is of prime importance to determine how such healing is brought about. It is by a process of cicatrization, as we are forced to admit by studying tuberculous lungs. This is true, at least of the ordinary productive lesions of the disease. It is barely possible that some of the purely exudative lesions may undergo a complete resolution. The rational procedure in attacking tuberculosis would seem to be by some means best suited to favor the fibrosis, which is recognized as an essential in the healing process of all pulmonary tuberculous lesions. A second and important point to be borne in mind is that a patient's life is not in great danger from the mere existence within his lung of a few localized tuberculous lesions, but of a dissemination of the infection throughout the lungs, and the question very naturally arises how, under ordinary conditions, it is brought abont. The majority of cases 
of pulmonary tuberculosis unquestionably begin with a single or with a few localized lesions usually in the apex nearer the posterior than the anterior surface, or, as Birch-Hirschfeld puts it, in the territory of the posterior apical bronchus. From this point the dissemination goes on more or less slowly through the bronchi and air cells, the lymph-vessels, and the blood-ressels. The two most important points to be considered in the local treatment of tuberculosis are: 1, how can we favor the fibrosis or cicatrization which constitutes the healing process of tuberculous lesions? and 2 , how shall we prevent a dissemination of the infection that already exists? In answer to the first, let me call attention again to the pathological observations that an unusual degree of fibrosis is seen in tuberculous lungs that have been for some time subjected to pressure. Dunin ${ }^{2}$ demonstrated, by a series of experiments on dogs that were made to determine the effect of compression upon the lung parenchyma, that in the neighborhood of small bronchi where slight infection had occurred there was a marked tendency to an overgrowth of fibrous tissue. When we stop to think of the mechanical condition of the lung we can readily understand that when this organ is subjected to a considerable pressure the various avenues by which infection is disseminated are occluded. The movements of the lung are diminished or absent and it is impossible for the softened material from foci that are breaking down to be aspirated into adjacent healthy portions of the organ. That compression must also exert a considerable inhibitory effect upon the lymph circulation in the lung is quite evident when we consider the physical state of the organ. Further than this, it is a well-known law of physiology that whenever an organ is put out of function its lymph circulation is impeded or abolished. Better than these theories, which explain in a very satisfactory way the imperviousness of a compressed lung to a dissemination of tuberculosis, are the findings in the dead-house, which show that whatever there may be in a compressed lung in the way of solitary or multiple tubercles, these lesions always bear evidence of age and of having antedated the condition which brought about the compression. Indeed, the question has been raised: Can fresh tubercles develop in a thoroughly compressed lung? For some time I have searched for material that will determine this question and I have never been able to find anything that might be looked upon as a recent tubercle in lungs that have been compressed for a considerable period. Relative to the same point, Fowler and Godlee ${ }^{3}$ say: "It would indeed be strange if tubercular disease could make rapid progress in a lung which is bloodless and airless and in which, therefore, all the ordinary channels through which the virus of the disease is spread, viz., bronchi, vessels and lymphatics, are more or less ob. structed." Rokitansky ${ }^{4}$, again speaking of the curability of tuberculosis, says: "Tuberculous pulmonary consumption is unquestionably curable, as we may infer from the appearances not infrequently observed in the dead bodies of persons who formerly had more or less suspicious thoracic affections and subsequently recovered. It is only by an investigation of the conditions under which these natural cures take place that we can hope to arrive at a truly rational mode of treatment." And further, "If the abscess (tuberculous cavity) be not too large it closes by a gradual approximation of its walls, which finally come in contact and coalesce. We then find in place of the previous cavern a cellulofibrous mass in which the bronchi end in blind sacs. This is of most frequent occurrence in the apices of the lungs, where the coexistence of open caverns and the presence of obsolete and cretified tubercles indicate the nature of the process that is here going on. The obliteration of a cavity of considerable size always occasions a corresponding depression of the surrounding parenchyma and a cicatrix-like folding and puckering of the pulmonary pleura, which is most frequently and distinctly observed in the case of those cavities which are often superficially situated quite in the apices of the lungs. The thorax is also depressed to an extent corresponding with the size and number of the closing vomicæ, as is obvious from the flattening and slight depression so frequently observed in the clavicular region. This process is undoubtedly favored very essentially by certain circumstances, amongst which we may enumerate the local depression of the thorax, the contraction of the cavity in consequence of the diaphragm abnormally pressed upward by the contents of the abdomen, the development of the emphysema in the parenchyma surrounding the cavern and bronchial dilatation."

Aside from the fact that compression exerts a favorable influence over the healing process in tuberculosis by favoring fibrosis and by limiting the infection, that is, occluding the avenues by which the tuberculosis may become disseminated through the lung, we must consider the mechanical condition of a tuberculous lung from yet another standpoint, and $I$ can do no better than to quote the remarks of Tidey: "In health the respiratory capacity of the lung is commensurate with the semi-circumference of the thorax. The diseased lung may be regarded as decreased in bulk, so far as function is concerned, by the amount of lung tissue involved. and it follows that the best mechanical condition of respiration would be secured by reducing the thoracic cavity in proportion to the reduced bulk of lung. Natural processes of repair tend to secure these conditions, but only lead to complete cicatrization when the disease is of a limited extent. We find, then, clinically, a flattening of the chest wall, dislocation of adjacent organs or hypertrophy of the opposite lung. In so far as the inflammatory element in phthisis is concerned. rest and relaxation of the inflamed tissues seem indicated and essential to the healing process. The English schools aim at developing the latent resources of the lung so as to compensate for the loss of the respiratory surface." Tidey sums up the advantages of mechanical support as follows: 1, in early stages, to give comparative rest and relaxation to lung tissue; 2 , in the stage of consolidation, to secure the same results, thereby limiting the risks of extension; 3 , in the stage of cavitation, to promote the closure of cavities by directing healthy lung to encroach upon diseased areas, instead of relying entirely upon natural process of cicatrization; 4 , diminished tendency to hemorrhage by reduced tension on vessel and cicatrical traction on walls; 5 , the ultimate object is to obtain a smaller thoracic cavity filled with healthy lung instead of an enlarged thoracic cavity partly filled with diseased lung.

In a previous communication many references were made to the writings of some of the older authors on the subjects of pleurisy with effusion, pneumothorax, etc., complicating pulmonary tuberculosis. These it is useless to repeat. Many of the modern writers realize the advantage of compression in pulmonary tuberculosis. Cornet $^{6}$ says: "In fact, we find as the result of the development of pleurisy with effusion or of pneumothorax, not so seldom an improvement, even if temporary, of the condition (of the tuberculous lung) that is hardly to be explained other than that it is the result 
of the compression of tissues in the neighborhood of the tubercle."

The general proposition that compression exerted upon a tuberculous lung favors cicatrization, and therefore the healing process, and that, so far as we know, tuberculosis of the lungs always heals by fibrosis or cicatrization, can not be lost sight of. That there is an enormous tendency for tuberculous lesions in the lung to heal is apparent from the great quantity of statistics that have been gathered bearing upon this point. Some of the most valuable of these observations are those made by Harris, ${ }^{7}$ who found that 39 per cent.

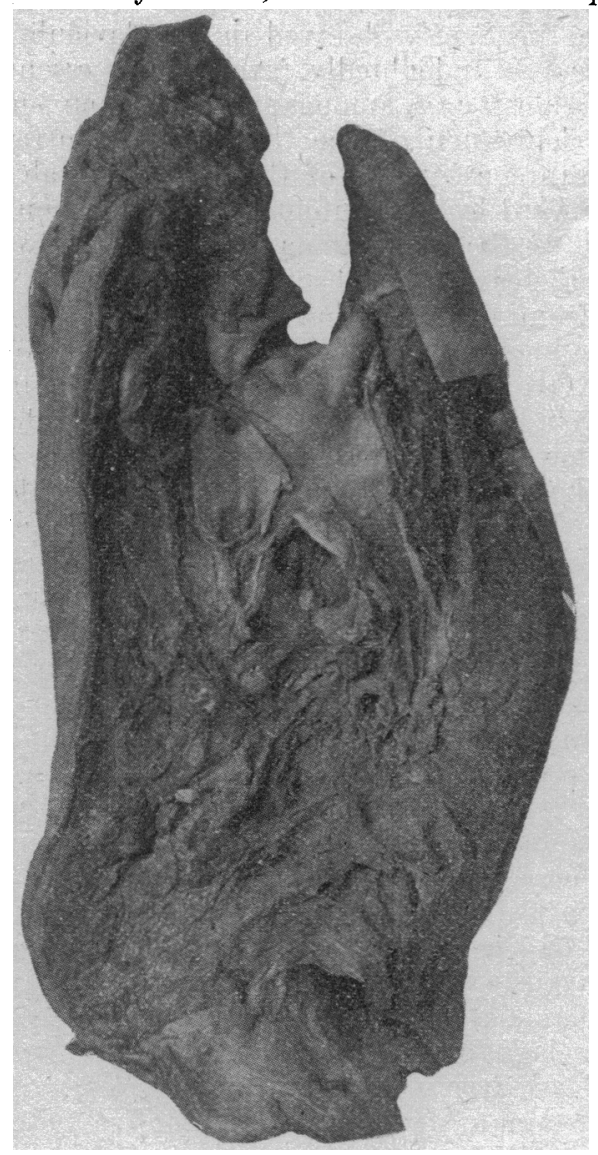

Figure $3 b$.

of all individuals who died from causes other than tuberculosis gave evidence of healed or latent pulmonary tuberculosis. Schlenkir ${ }^{8}$ found the same in 44 per cent. of the cases he examined. Birch-Hirschfeld ${ }^{\theta}$ found, in an examination of 196 bodies dead from accidents, that 21.4 per cent gave evidence of healed or latent pulmonary tuberculosis. With this as a basis, we must conclude that, as far as local treatment is concerned, we have two important indications to be met. Both of these are pointed out to us when we study the pathology of the healing of tuberculosis in the lung. Given focus of tuberculosis in the lung, we must accomplish what nature always endeavors to do, first, to promote the development of scar tissue in and about the diseased area, and, until this is completed, to prevent the dissemination of the disease by occluding the various avenues that make this possible. Kurlow and Green (quoted by Cornet) demonstrated that in areas of healed tuberculosis, made up entirely of scar tissue or of scar tissue enclosing calcareous material, no virulent bacilli were found. As long as the center of the focus is caseous, virulent bacilli are present and are capable of renewing the disease the moment the barrier is broken.
While there is no doubt that in the majority of cases the areas of healed tuberculosis consist of scars enclosing caseous or calcarous material, we may find as the only remnant of a tuberculous infection one or more thick-walled cavities, from which tubercle bacilli have disappeared. This may gradually and slowly heal as it result of contraction of its fibrous capsule, but much more commonly the mechanical conditions are such that definitive healing is impossible. In such cases these cavities may be a constant source of annoyance to patients, in that they have an active secreting surface which keeps up a continuous cough with expectoration. Case 5 of our first report ${ }^{10}$ illustrates this condition very well. The patient was a strong, rugged man of 30 , who had had tuberculosis of the right lung five years. During the first two years of his illness he coughed violently, expectorated freely and had several attacks of hemoptysis. His weight had been reduced from 160 to 117 pounds. During the third year he coughed and expectorated less and his weight reached 135 pounds. During the fourth year there was a gradual improvement. At the time of our first examination, September 5,1898 , he complained of having paroxysms of cough with much expectoration; he had no fever; his weight was normal, and he was able to be at work. There were no physical signs in the lung except scattered crepitant

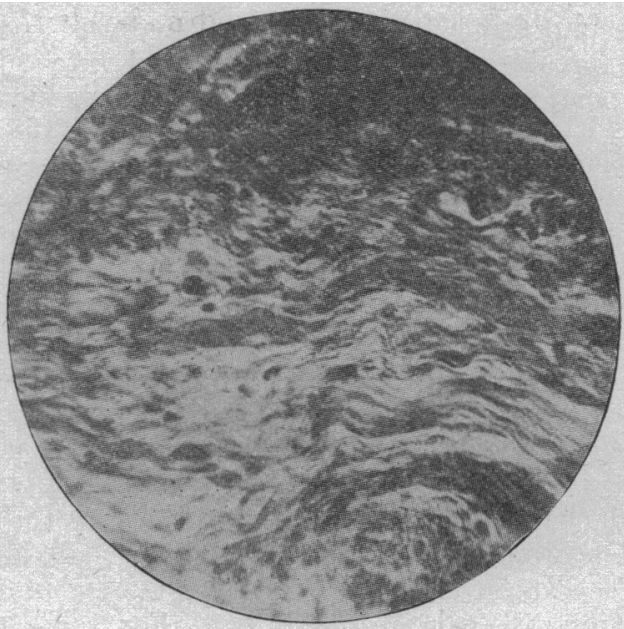

Nig. 4. Fibroid area from compressed lung-high power. Sertion through a healed tubercle

râles in the right lower lobe. Tubercle bacilli were demonstrated in the sputum. On September 7, 171 cubic inches of nitrogen were injected into the right pleural cavity. In this case we had supposed, on account of the paroxysms of cough with free expectoration, that a cavity existed which was more or less centrally located and which, therefore, gave rise to no physical signs. The compression was so thorough that the cavity was evidently emptied of its secretions, as the patient expectorated very freely immediately after the operation. He has been examined repeatedly since that time and every evidence of the disease in the lung had disappeared. There is no more cough or expectoration, and the patient even insists that the drum-stick finger ends and the curved nails are becoming less and less pronounced.

In our first publication on this subject, it was pointed out that pulmonary hemorrhage, the result of tuberculous disease, might readily be controlled by injecting nitrogen into the pleural cavity and thus thoroughly compressing the affected lung. Five cases of hemoptysis due to tuberculosis have been injected within the last year and in each instance it was possible to check the 
hemorrhage a.lmost immediately. One of these, $\mathrm{Mr}$. H. s., a very pale, anemic individual, consulted us for repeated attacks of blood-spitting. At the time of his first examination he was expectorating a bloody material, which upon microscopic examination contained great quantities of tubercle bacilli. There were physical signs over the entire upper lobe and a few scattered râles over tile left apex. His weight was 147 pounds, a loss of ten pounds since the onset of the disease. The physical signs were so much more widespread over the right lung that it was concluded the hemorrhage had its origin there, and it was decided to inject the right pleural cavity with nitrogen and check the hemorrhage by thoroughly compressing the lung. The operation was repeated at intervals of one to three weeks until four injections had been made, when the physical signs had practically disappeared from both lungs; he had gained 23 pounds in weight, which was 12 pounds in excess of his normal weight, and all symptoms of disease had subsided. The hemorrhage was checked immediately after the first injection and has never recurred. In the other cases there was no difficulty in controlling the hemorrhage when it was possible to compress the lung thoroughly. At the last meeting of the American Climatological Society, H. P. Loomis, of New York, reported some cases of pulmonary hemorrhage treated by intrapleural injections of nitrogen and stated that he had never failed to control the hemorrhage absolutely. As early as 1885 Cayley ${ }^{11}$ induced an artificial pneumothorax on the left side to check pulmonary hemorrhage. He simply made an incision in the thoracic wall, introduced a double tube and in that way created an ordinary open pneumothorax. During the night following Cayley's operation his patient had two attacks of hemoptysis, spitting up four ounces and two ounces of blood. This is the earliest record that $I$ have been able to find of an attempt to check pulmonary hemorrhage by the induction of pneumothorax. The method of Cayley, it is very evident, gives rise only to a pulmonary collapse and is much more difficult and dangerous than the simple procedure of injecting the pleural cavity with nitrogen until an actual positive pressure is obtained and the lung not only collapsed but considerably compressed. Williams, in his work on pulmonary consumption, advised the introduction of a styptic solution-tannic acid-directly into the bleeding cavity. The objection to this procedure is that the exact point of bleeding can not usually be determined and that the method involves much more risk than the simple intrapleural injection of nitrogen. These cases of pulmonary tuberculosis associated with hemoptysis not infrequently develop a considerable fever and other symptoms indicating increased absorption at the site of disease or perhaps more or less acute dissemination of the infection, and it is interesting to note the rapid diminution of fever following the injections, indicating in all probability that the absorption of toxic substances is interfered with as the result of the thorough compression of the diseased organ.

One of the greatest dangers that confronts a patient who has pulmonary tuberculosis is the infection of his respiratory tract with organisms that give rise to what is ordinarily known as a secondary or mixed infection. The important part played by this secondary infection, such as the production of bronchitis, in that way favoring a dissemination of tuberculosis, and aiding in the softening and breaking down of tubercular foci is too well known to be considered in detail at this time. The avenues by which this secondary infection is carried into the various parts of the lung are occluded, thus favoring the chances of healing of the tuberculous lesion. Subsequent to the compression of tuberculous lungs, the fever and expectoration diminish so markedly that we are forced to conclude that the rôle of the secondary infections has been reduced to a minimum. Furthermore, it is known that so long as tissues infected with tuberculosis are also exposed to the action of pathogenic micro-organisms the healing process can not be completed. Whatever there is in the direction of cicatrization is undone by the pyogenic organisms, when they are present in sufficient quantities. This is very well illustrated by the work of Prudden, who demonstrated by experiments upon rabbits that the mixed infection is largely responsible for the exudative phenomena and the cavitation in lungs previously infected with tuberculosis. The tissue changes so essential to the process of healing of tuberculosis are very much interfered with by the mixed infection, and in the general hygienic treatment of tuberculosis of the lungs one of the first indications has been to get rid of the secondary element of the infection. As Cornet puts it, healing of a focus of tuberculosis in the lung is probably always altogether the result of tissue changes which diminish or inhibit the absorptions of proteins derived from the bodies of tubercle bacilli.

One of the most difficult propositions in connection with this work has been the selection of cases suitable for the injections. In connection with our earlier cases we made it a rule to inject only those in which the lesions were unilateral and in which but one lobe was involved. A great number of our cases, however, have been operated upon in spite of the presence of the disease on both sides and the two questions rather difficult to decide in these cases are first, will the remaining area of respiration after compression of one lung be sufficient to maintain life. when the opposite lung is also more or less involved: and, second, will there be a disposition on the part of the functionating lung in the direction of rapid spreading of the disease already existing? Within the last year a considerable proportion of the cases operated upon have had bilateral lesions and in many of them there has been a marked general improvement in spite of the widespread distribution of the disease. It has been suggested that the increase of function called for in one lung when its fellow is compressed will tend to disseminate the infection; that the increase in the pulmonary excursions would favor an aspiration of infective material and that if compression and complete suspension of function in one lung will favor the healing of tuberculous lesions, a vicarious emphysema or hyper-function will have the opposite effect. This assumption is incorrect both in theory and in practice. It must be remembered that the lung is inclosed in a bony cage that makes it impossible for its excursions to be much increased beyond the normal. A number of the cases included in the first report show conclusively that there is no tendency to an increased activity of the disease in the functionating lung when its fellow is compressed. One of our cases ( $\mathrm{No} .49$ of the first report) who dereloped a tuberculosis of the left upper lobe, some time after he had been injected for a tuberculosis of the right lung, has had eight injections on the left side without the slightest tendency in the way of a relighting of the disease in the right lung. At a recent examination both lungs were found entirely free from physical signs, except a pleural rub on the left side, and two months have elapsed since his last operation. In this case one lung or the other has been compressed at different times for a period of twenty months and at 
his last examination the patient was found nearly free from cough; his temperature and pulse normal and for the present at least he may be considered as having recovered from a bilateral tuberculosis that involved both upper lobes and the apex of the lower lobe on the right side. Forlanini, of Italy, in a personal communication to us about a year ago stated that he dic not consider a bilateral distribution of the disease a contraindication to the compression treatment.

In several cases of very acute tuberculosis involving an entire lobe or the greater part of a lung, I have been called upon to compress the affected lung to stay the infection until the patient's general condition might improve sufficiently to admit of a change of climate and a continuation of treatment in the ordinary way. At the last meeting of the American Climatological Association. Dr. R. H. Babcock, of Chicago, for whom I have made a number of injections, stated that the compression seemed to him "to start the patients in the right direction."

On account of the frequency with which we meet pleural adhesions in the dead-house in bodies dead of tuberculosis of the lungs, it was believed that the ma-

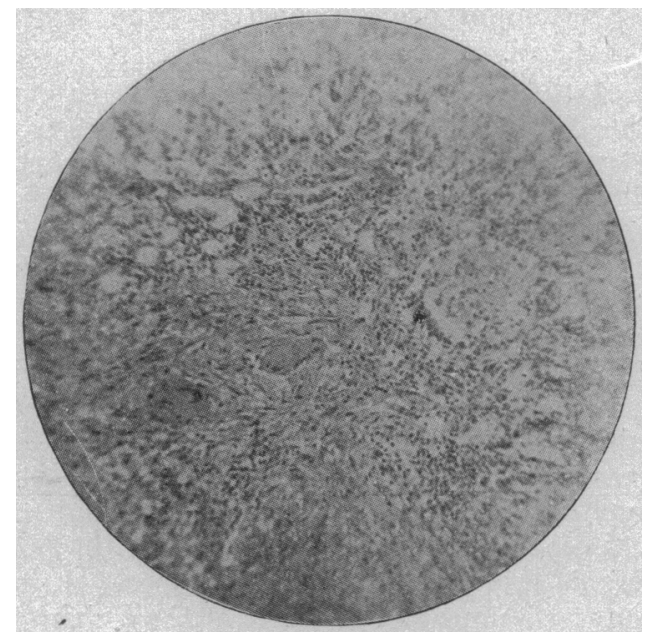

Fig. 5.-Section through acute tuberculous area in uncompressed lung.

jority of the cases that might apply for treatment would show pleural adhesions to such an extent as to make a compression impossible. In practice, however, we are forced to abandon the operation in only about 5 or 6 per cent. of the cases on account of pleural adhesions. It must be remembered that adhesions may be present here and there over the surface of a lung without interfering in any way with a thorough compression. Occasionally adhesions may be present anteriorly or laterally so that the needle must be introduced posteriorly and the lung compressed against the anterior thoracic wall. Mohr ${ }^{12}$ studied the mode of displacement of the lungs in pleurisy with adhesion. In 23 cases in which there were no adhesions the lung was compressed in the usual manner against the vertebral column and mediastinum. Thirteen times it was compressed from below upward; 4 times from within outward; 4 times from behind forward; 4 times from before backward, and once from above downward. In some of our cases it has been necessary to puncture the thoracic wall at several points in order to find an area free from adhesions, and frequently we have in this way been able to bring about a considerable degree of compression in spite of circumscribed areas of adhesions.

It is impossible to determine by the usual methods of physical diagnosis whether or not adhesions exist. When a considerable pulmonary excursion can loe demonstrated by percussion over the lower border of the lung, or when Litten's diaphragm phenomenon is present there is no doubt as to the absence of adhesions that will interfere with compression. There are many cases, however, in which these signs are absent, perhaps on account of the extensive infiltration of the lung, in which no adhesions are present and therefore it is impossible to deternine whether or not the lung can be compressed until the needle has been introduced. On account of the danger of puncturing the lung and injecting the gas directly into the lung parenchyma, or perhaps into a vein, it is wise to determine whether or not the point of the needle is in the pleural cavity before attaching the tube. This can usually be very readily accomplished by instructing the patient to take a series of deep breaths as the needle is being introduced, when, if the point of the needle be within the free pleural cavity, a current of air can be heard to rush through the needle. In this way it is almost always possible to ascertain when the point of the needle is in the free pleural cavity. It is advisable to determine this point definitely, because of the slight danger from gas embolism in the event that the needle

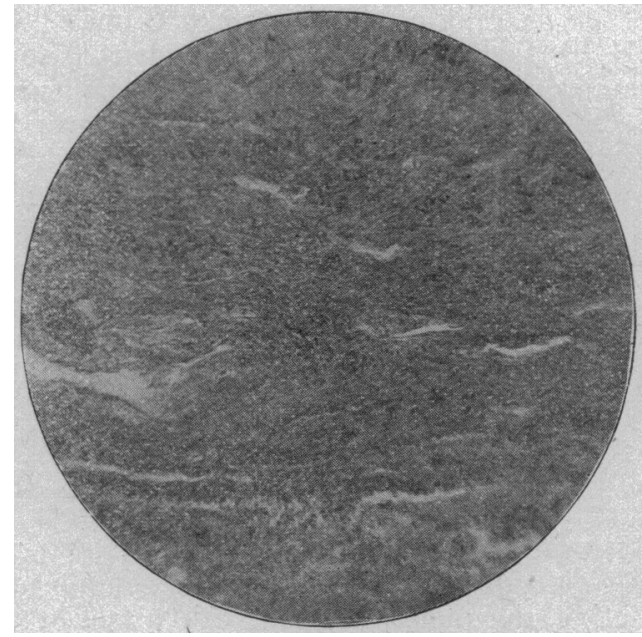

Fig. 6.- Section through old tubercle in compressed lung. Low power.

has been inserted into the lung and perhaps into a vein. With the exception of this point the technique of the procedure need not be repeated at this time. (See THE JouRnAL, Oct. 14, 21 and 28, 1899.)

As regards the possible accidents of the operation I may state here that there have been no unpleasant symptoms in any of the cases operated upon since the one referred to in the first communication, and since the adoption of the intercostal compress no cases of subcutaneous emphysema have been observed to follow the operation.

The hemiplegia that is known to develop occasionally in connection with diseases of the lung or pleura, or during and after various operative procedures upon the thorax that involve the lung or pleura, can not always be explained readily, and is not always due to the same cause. It is possible that a small clot may be dislodged from a thrombosed vessel and carried to the brain, and may cause a temporary or permanent hemiplegia. In some cases undoubtedly the hemiplegia is to be explained on the assumption that a gas embolism has occurred. Some observers believe that the paralysis is due to a local metastatic encephalitis, and still others believe the pleural irritation in some obscure, reflex way is responsible for the transient or permanent paraylsis that ensues. The possibility of this accident should al- 
ways be borne in mind, but its actual occurrence is too rare to be considered a serious objection to the operation. In a few cases patients have complained of numbness and tingling in the hand or the entire arm on the side of the operation, but this has always disappeared very promptly. The danger of hemorrhage from puncture of an intercostal vessel is scarcely to be given a serious thought, as no instance of it has occurred in the more than 600 thoracic punctures that we have made in connection with this work.

The danger of infecting the pleural cavity with the ordinary aseptic and antiseptic precautions taken is scarcely to be considered, as in all of the cases that have been injected there have been but two instances of pleurisy with serous effusion, and it is certainly unfair to conclude that these were due in any way to the injection of nitrogen.

During the past year we have been in the habit of making the injections somewhat more frequently than we did previously in order to keep the pleural cavity at all times well filled with gas and thus keep up a continuous compression of the lung for a period of several months, depending largely upon the patient's general

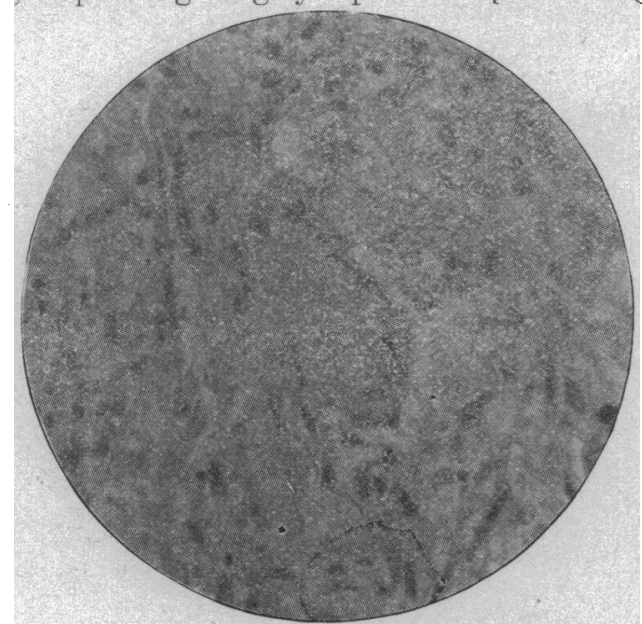

Fig. 7 .-Section through acnte tuberculous area in uncomplessed lung. Low power.

condition and the physical signs detected in the lung when once the gas has been allowed to be absorbed.

The only objections that have been made to the procedure, so far as I am aware, are those of Samuel West, ${ }^{18}$ who does not think that the rationale of the procedure is based on conclusive evidence. He believes that recent tubercle may be found in a collapsed lung, all evidence going to show that it developed after collapse, and that collapse of one lung is frequently followed by derelopment of tubercle in the other lung.

In the Transactions of Clinical Society of London, Vol. xviii., West collected 24 cases of pneumothorax which recovered. The probable cause is specified in 18 cases. He states that 4 were certainly and 4 more probably due to phthisis; the others were due to emphysema, overexertion and injuries. West's own case was one of a young man who for some weeks had been an outpatient of the Royal Free Hospital and was thought to be phthisical. West says that "The cause of the pneumothorax we may assume to be phthisis, and the effusion of air appears to have acted in this case as the effusion of fluid often does, and for the time to have checked the progress of the disease."

The effect of compression upon the blood-supply of the lung has been the subject of considerable dispute and there seems to be some doubt as to whether a compressed lung is hyperemic or anemic. Some observers believe that the good effect of compression in pulmonary tuberculosis is due to the hyperemia and edema to which the lung tissue is subjected in its compressed state. Fütterer $^{14}$ reports a case in which the pneumothorax was due to rupture of the pleura pulmonalis of a tuberculous lung, and states that he "decided to wait some weeks to allow the patient to recover somewhat from the severe nervous shock he had experienced and to gain some strength as well as to permit the perforation to heal up, if the healing process could be established, and to put the supposed tubercular changes of the lung under the beneficial influence of edema and hyperemia, which are both present to a high degree in a collapsed lung, and which no doubt are powerful means of destroying the tubercle bacilli." In this connection it may not seem amiss if we refer again to the immunity from tuberculosis of individuals who suffer from valvular disease of the heart, giving rise to more or less passive congestion of the lung tissue. Eichhorst ${ }^{15}$ says that a combination of pulmonary tuberculosis with valvular lesions of the heart is not so uncommon as was supposed. Statistics of Frommelt and Kidd show that from 7.2 to 8

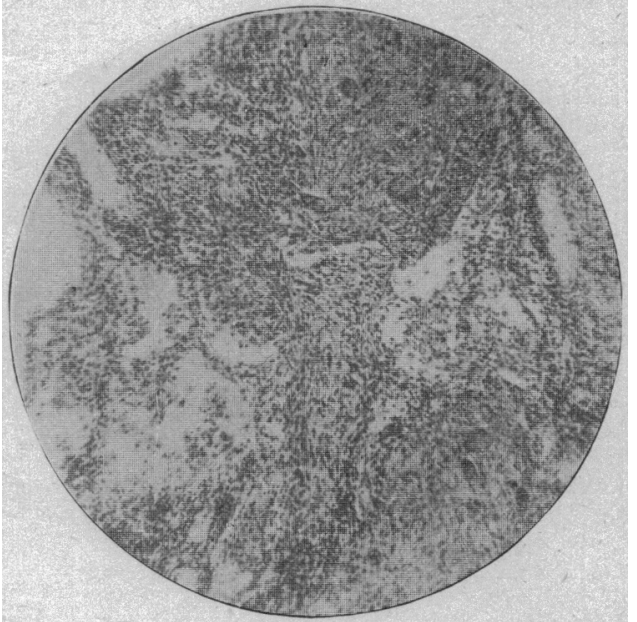

lig. 8.-Acute tuberculous area in uncompressed lung. Iow power.

per cent. of cases of valvular heart disease have tuberculosis of the lung. Potain found that 16.4 per cent. of ases of mitral stenosis are complicated with tuberculosis of the lung, and it is to be remembered that mitral stenosis, above all other valve lesions, gives rise to the greatest degree of pulmonary stasis, and therefore might be expected to give the greatest immunity to this disease. In Eichhorst's clinic 2 per cent. of the cases of tuberculosis of the lungs had valvular heart disease. On the otiue hind, therc can be no doubt that in congenital stenosis of the pulmonary artery tuberculosis of the lungs is the rule. These statistics force us to the conclusion that in congenital pulmonary stenosis tuberculosis of the lung almost always supervenes snoner or later, but that mitral valve lesions do not by any means afford the degree of immunity to tuberculosis of the lungs that we formerly ascribed to them. That a lung thoroughly compressed must be comparatively anemic seems reasonable when we consider the mechanical change alone. The difference in weight between an atelectatic lung of a stillborn infant and that of an infant after a few respirations have been made would seem to be satisfactory proof of this. Schäfer and Symington $^{16}$ state, for example, that the lungs before birth weigh about one ounce and a half, but after com- 
plete expansion by respiration they weigh as much as two and one-half ounces.

During the past year we have made a series of experiments on dogs to determine the effect of compression upon healthy lung tissue, particularly the effect upon individual air cells. It has been urged that when compression of a lung has been maintained for a period of months, or perhaps a year, some of the air vesicles must be permanently damaged to the extent of partial or complete obliteration from prolonged contact of the opposing intra-alveolar surfaces. Clinically, from a consideration of cases of pleurisy with effusion and empyema in which the lung tissue is reduced to a compact mass and held in that position for a considerable period of time, we know that no great damage is done in the direction of alveolar obliteration. Even in empyema, in spite of pleural adhesions that are present wherever the lung is forced against the parietal pleura, expansion follows gradually and slowly as soon as the pressure is removed. In the majority of these cases the lung expands almost entirely, and would always expand completely but for the limiting adhesions. In the cases of pulmonary tuberculosis that have been treated by

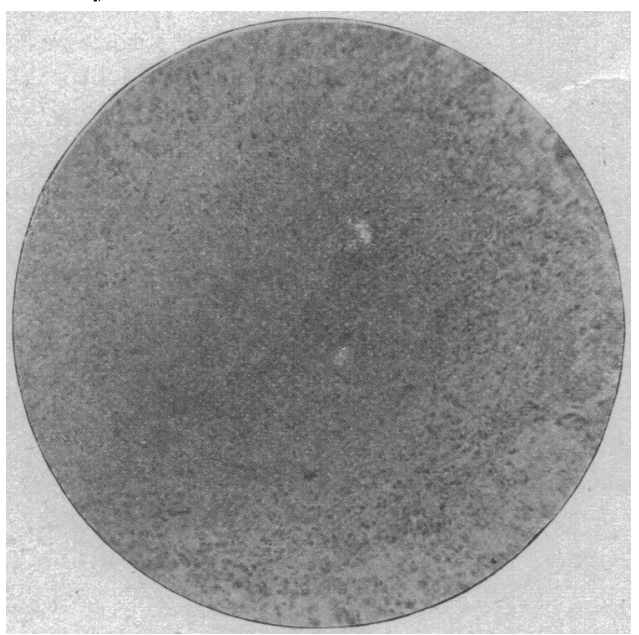

Fig. 9.-Acute tuberculous area in uncompressed lung. I.ow power. Marked necrosis.

compression there has never been any doubt as to the reexpansion of the lung after the gas has been allowed to become absorbed, even when the compression has been maintained as long as six to eight months.

To enable us to study the histologic changes in healthy lung tissue subjected to compression and to determine the effect upon the pleural surfaces, eight dogs were selected, the thoracic wall was prepared aseptically and nitrogen gas injected at intervals of from one to two weeks for a period of eight months. In four dogs normal-salt solution was substituted for the nitrogen. The gas was injected until the dogs became thoroughly dyspneic and until the respiratory sounds were altogether obliterated. I shall not repeat the records of these experiments in detail at this time, but limit myself to those findings that deal directly with the matter under discussion. No difficulty whatever was experienced in making the injections except that the mediastinum was ruptured in the second dog operated upon. This is an accident likely to occur in the dog, on account of the very thin mediastinal membrane. In the human subject the possibility of this accident need not be considered, as the membranes are very much thicker. The normal-salt solution was absorbed with greater rapidity, and, on account of its greater weight, it could not be injected in quantities sufficient to com- press the lung so thoroughly as was the case with the nitrogen injections. Eight months from the time of the first injections the dogs were killed, the trachea clamped and both pleural cavities freely opened. The pleural surfaces were smooth and shining everywhere and, in fact, altogether free from changes, with the exception of a slight thickening of the pleura pulmonalis over a limited area in the sulcus interlobaris. The left lung was almost completely compressed, although it still crepitated slightly and floated in water. (Fig. 1.) In four instances the lungs were separated, a canula was tied into the left bronchus and inflation attempted. Over some of the dark, thoroughly atelectatic areas some little force was necessary, but at no point was it impossible to inflate the air cells thoroughly. The bronchi werc then tied, the lung immersed in 5 per cent. formalin solution in water for twenty-four hours and then cut into small pieces for imbedding. Aside from slight epithelial desquamation, which was also found in the opposite non-compressed lung, no changes of any kind could be detected in the tissues. From the other four lungs pieces were prepared in their compressed state, and here also no changes could be detected.

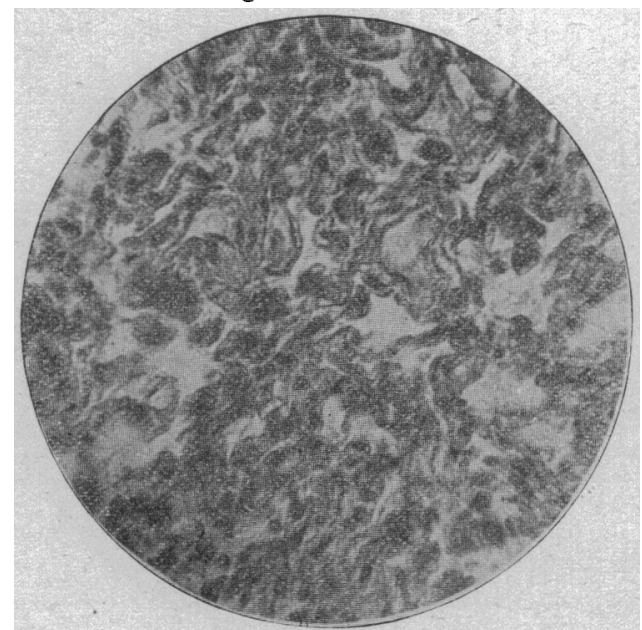

Fig. 10.-Alea of compressed lung. High power. No tubrreles. Air vesicles completeiy compressed.

These experiments merely proved, first, that nitrogen yas or normal-salt solution could be injected into the pleural cavity frequently and at short intervals without giving rise to infection or in any way causing untoward effects, and second, that healthy lung tissue may be kept in a state of thorough compression for a period of at least eight months without causing obliteration of air cells or in any way interfering with the re-expansion of the lung as soon as the cause of compression is removed.

At the last mecting of the Association 1 exhibited a specimen of tuberculous lung from a case of longstanding pleurisy with effusion which finally became purulent. The patient, Mr. M. A., aged 46, died as the result of his pulmonary tuberculosis soon after an operation for the empyema. He was admitted to Alexian Brothers' Hospital, Chicago, on Jan. 19, 1900. Eight years before, he had developed a pleurisy with effusion on the left side, which was aspirated several times, but in each instance recurred. His attack of pleurisy had been preceded by severe cough with expectoration, the result of a tuberculosis of the left lung. In spite of the fact that the effusion persisted, he remained in good health for a number of years, and in fact was feeling well until three weeks before his admission to the hospital, when he developed a severe cough 
with profuse expectoration, great shortness of breath and extreme weakness. It is noted on the history that he expectorated much mucus and very little purulent material. The physical examination showed the signs of the presence of fluid on the left side, an aspirating needle was introruced and the purulent nature of the fiuid demonstrated. On account of the extreme shortness of breath it was decided to operate in spite of the fact that the physical signs on the right side denoted a diffuse acute tuberculous infection of that lung. The patient died twenty-four hours after the operation. At the post-mortem the left lung was found reduced to about the size of the fist and thoroughly bound down by adhesions; the right lung was literally studded with fresh, grayish tubercles, varying in size from a millet seed to that of a pea, with an old thick-walled cavity in the apex. (Fig. 2.)

It is interesting to note in this case that the few scattered tubercles in the left (compressed) lung are made up of thick scars enclosing calcareous material, all evidence going to show that they are old, and in all probability antedated the pleurisy with effusion that brought about the compression. In the opposite lung there is an acute diffuse miliary tuberculosis. This further bears out the view that tubercles can not develop in a thoroughly compressed lung, because of the fact that the avenues by which the infection is disseminated are occluded.

\section{CONCLUSIONS}

1. Tuberculous lungs after compression show much fibrosis in and about the foci of disease; hence, extension from these foci is less likely to occur.

2. Tuberculous lesions probably never heal by resolution, always by cicatrization-this is particularly true of lung tuberculosis. Hence, in attacking them it is rational to further the natural tendency to cicatrization.

3. The danger of pulmonary tuberculosis does not lie in the presence of one or more foci of the disease, but in a dissemination of the infection throughout the lungs or the body generally.

4. Healing is probably, as Cornet puts it, altogether the result of tissue changes which inhibit or diminish the absorption of proteins derived from the bodies of tubercle bacilli.

5. Areas of healed tuberculosis may consist of: Scars, perhaps enclosing caseous or calcareous material, or of cavities lined with a thick wall. Kurlow and Green (Cornet) have demonstrated that in areas of healed tuberculosis made up entirely of scar tissue or of scar tissue enclosing calcareous material no virulent bacilli exist.

6. Tuberculosis in the lungs spreads either by contimuity and contiguity or by dissemination of the rim through, 1 , the air-channels ; 2 , lymph-vessels ; 3 , bloodressels.

\%. Good effects of compression, locally, are brought about by the limitation of areas of disease already existing, by favoring fibrosis in and about these areas; by occluding the avenues of dissemination of the virus, and by compressing cavities to enable them, mechanically, to heal.

8. Other effects of compression are due to rest to the orgar as a whole, emptying of secretions, prevention or diminution of absorption of toxic bodies, prevention of secondary infoctions, the diminished tendency to hemorrhage.

9. There is no evidence that fresh tubercles can derelop in a compressed lung.
10. Pleural adhesions are less common than might be supposed from a study of material in the dead-house. The lung may retract in various directions on account of circumscribed areas of adhesion.

11. Healthy lung tissue may be compressed for a year or longer and retain its capacity for expansion upon removal of pressure.

12. The actual risk of the operation of intrapleural injections of nitrogen is very slight. No accidents have occurred since the first report was inade.

13. Subcutaneous emphysema may easily be avoided by using the intercostal compress.

14. Uses of intrapleural injections of nitrogen: 1, curative in pulmonary tuberculosis for reasons mentioned above; 2 , palliative-to prolong life for weeks or months, though the disease be too extensive to make recovery probable; to diminish fever and expectoration; 3 , to check pulmonary hemorrhage; 4 , to compress cavities, tuberculous and others, and establish mechanical conditions that will permit their healing; 5 , to compress the lung just prior to surgical operations in which the pleural cavity is to be freely opened and to determine presence or absence of pleural adhesions before opening pleural cavity to drain absecses or bronchiectatic cavities, cysts, etc.

BIBLIOGRAPHY.

1. Wurtemb. Cspdbl., Bd. Iviii, No. 14

2. Virchow's Archiv, Vol, cii, p. 323 .

3. Diseases of the Lungs, 1898.

4. Pathological Anatomy-New Sydenham Society's Translation. 1850

5. On the Mechanical Support of the Lung in Phthisis, Brit. Med. Jour, 1896, p. 721 .

6. Nothnagel's Specielle Path. und Therapie, Vol. xiv, H. 3.

7. Brit. Med. Jour., Dec. 21, 1889.

8. Virchow's Archiv, Bd. cxxxiv, p. 145.

9. Bericht ueber den Congress zur Bekaempfung der Tuberkulose als Volkskrankheit. Berlin. 1899.

10. The Jovrnal, Oet. 14, 21 and 28,1899

11. 'Trans. Clin. Society of London, Vol. xviii.

12. Beiträge zu einer künftigen Monographie des Empyems, Kissengen, 1839

13. Brit. Med. Jour., Nov. 27, 1897.

14. A New Method of Treating Pneumothorax, Medicine, 1896. 2, pp. 474-480.

15. Spec. Path. und Ther.,.Bd. iv, p. 550.

16. Quain's Anatomy, 10th Ed., Vol. iii, part 4, p. 181

DISCCSSION ON PAPERS OF DRS. FLEUdeNTHAL, ANDERs, EISON, AMBLER, MAYS AND LEMKE, *

Dk. Victor C. Vaughian, Ann Arbor, Mich.-I listened to the papers read with interest and with profit. The diagnosis of the prebacillary stage of tuberculosis is important, because that is the time when it should be diagnosed if we wish to accomplish anything in the way of treatment. I am much interested in the remarks made in reference to temperature as a means of diagnosing tuberculosis. I believe that the temperature curve in tuberculosis is much more typical than it is in typhoid fever, although there may be various conditions which affect the temperature curve, such as exercise, which influences it very much. I almost invariably have the patients take it at 8 a.m., at $12 \mathrm{~m}$., and at 4 and 8 p.m. When the temperatures are taken at these hours the highest temperature will be found almost invariably at 4 p.m.

As to the possibility of complete recovery from tuberculosis, it is no doubt a question of restitutio ad integrum. In cases of peritoneal tuberculosis, where a laparotomy had been performed for that condition, and where, years afterward, another laparotomy was done for a hernia or something else, it has been found that the tubercular lesions had disappeared. Two years ago $I$ took a large number of rabbits and inoculaterl them with virulent cultures of the tubercle bacilli; after a lapse of six weeks one-half that number had their abdominal cavities opened; in these cases we saw tubercular nodules, some of which were cut out and subjected to a microscopical examination, showing conclusively the presence of the tubercle

* Dr. Anders' paper was published last week; those of Drs. Frendenthal, Edson and Ambler were published elsewhere. 
bacilli, not only in the instances where there were tubercular lesions in the omentum and peritoneum, but also over the liver, which was dotted with tubercles. All these that were operated on lived, while the control animals all. or nearly all, died. Of course, statistics show us, as well as the observations, that tuberculosis is most easily curable. Rest, I am sure, is a great factor in the treatment of tuberculosis, and this is the reason why great benefit is obtained from sanatoria treatment. The question as to the amount of exercise and to what extent the patient should rest must be decided by each individual case. Where there is much temperature there must be complete rest. When the patient is not in a febrile condition, or the tempera. ture is not above 100.5 or 101, considerable out-door exercise may be indulged in. Out-door life in the Western part of the United States or in Colorado is a good thing, but we do not utilize it enough in the treatment of tuberculosis-as we should. I recall a severe case of tuberculosis occurring in a patient who lived several miles from my office; this patient came every day to my office for treatment, rain or shine, cold or warm; the cough disappeared, the bacilli disappeared and the patient was apparently well. Out-door exercise is not as much utilized as it should be.

Dr. Mays' paper is certainly an interesting one. I had occasion some time ago to write an article on argyria, and I was surprised in looking up cases to find so many had developed tubereulosis when they were saturated with nitrate of silver. It does not seem to me that it is curative under these conditions.

Dr. DeLancey Rochester, Buffalo-Regarding the paper of Dr. Freudenthal, showing the effect of occupation, he mentions tailors particularly. It struck me that one of the chief dangers in tailors suffering from tuberculosis was from the dissemination of the disease. It is their habit to bite and wet the thread and then to go on sewing; in this way they can get the tubercle bacilli distributed widely. The tailor-shop is a marked factor in the spread of tuberculosis. I am also glad he spoke of the common occurrence of the disease of the upper air-passages associated with tuberculosis. In almost all cases of tuberculosis we find more or less disease of the nose and, particularly of the nasopharynx, and sometimes of the ton sils. The nasopharynx is particularly a nidus for the microorganisms. I have many cases in which a careful examination showed a secretion flowing in large amounts, quite persistent. and the washing away of the secretions resulted in disclosing other symptoms of pulmonary tuberculosis.

Dr. Anders referred to the prebacillary stage of tuberculosis; in this stage the temperature should be carefully watched. There is another point to which I wish to refer, the temperature as it occurs in the healthy. Observations show that there is a normal temperature curve, the lowest point being reached between the hours of 12 and 6 a.m., and the highest between 12 and 6 p.m. But these observations are not numerous enough to make statements absolutely reliable.

Dr. Edson has brought out the very great importance of rest. The index in regard to the question of rest is to be found in the pulse, the temperature, as well as the physical signs. To place a person at active exercise when he has a marked elevation of temperature, and other evidences of an active inflam. matory process, or evidences of softening or a bronchitis, with danger of breathing scattered tubercle bacilli into the lungs and exciting the pneumonia, tubercular in origin, would be a great mistake. Rest is of great importance in the presence of numerous râles.

In regard to the case of Dr. Ambler, that of serum-therapy it is not such a remarkable one when we consider that these cases are treated in a sanatorium, in a climate where cases recover without any other treatment at all, and where they naturally get well. So, I hardly think one can lay the good results obtained to any serum, particularly when we believe they will get well without it. The sanatoria treatment of tuberculosis is the best treatment these patients can get. At Saranac Lake these patients get nothing in the way of medi cine except cod-liver oil, and nearly all cases get well. Rest and out-door exercise is the treatment.
Dr. Lemke's report is interesting as bearing on rest. His statement shows remarkable improvement in cases where there was a chronic pneumothorax. This year I had two cases under observation. In one the pneumothorax had persisted for several months. This case, after the development of the pneumothorax, progressed badly, became decidedly worse, the patient lost flesh rapidly, etc. In the other case, operated on without benefit, except some relief from the dyspnea, there was no pus present until after the operation. Neither of these cases im. proved by the spontaneous recurrence of pneumothorax, which persisted for several months. In one case at the General Hospital, the local lesion was a very slight one indeed.

Dr. Vaughan referred to cases that were saturated with nitrate of silver. I think he has mistaken Dr. Mays' meaning entirely. In Dr. Mays' treatment the silver nitrate is injected to prevent irritation of the vagus, and so affect the innervation of the lung, that was the point. 'The case was certainly interesting and instructive. He stated, however, that the cases were practically well. I wish he would tell me what he means by practically well. We know perfectly well that a large number of cases of tuberculosis improve under any treatment instituted. We should remember to treat the patient and not the tuberculosis simply; each individual case requires special study; some cases require one thing and some cases another. There was one case in Buffalo where there was an excavation at the apex, with infiltration at the other apex and at the base, and that case recovered without any specific treatment beyond out-door life and guaiacol in moderate doses.

Dr. S. Solis-Coher, Philadelphia-My views on the causation of tuberculosis have been quoted. I have slightly modified them since that article was written. My present position is this: First, there is a fundamental trophic failure, congenital or acquired through privation, depression or excess. Then the invasion of Koch's bacillus - in rare instances another microbe, perhaps warranting a separate category for such cases-accompanied by definite histological thanges and toxemia comparatively mild; then, with the invasion of pus or. ganisms and similar microbes, a breaking down of tissue and a severe toxemia, with the phenomena properly called phthisis. As the trophic failure is fundamental in pathology it gives the clue to fundamental treatment. The patient's nutrition must be improved to the highest possible point. Rest may be neeessary in some cases, and usually is when there is tendency to persistent elevation of temperature to or beyond $100 \mathrm{~F}$.; but even rest should be in the open air when possible. Out-don exercise in proper cases is of the greatest value. In this connection I may recall attention to a case of recovery which $I$ re. ported at the meeting of The American Medical Association at Newport, to illustrate the benefit of compressed air; that patient has remained well these thirteen years since that meet ing, and keeps her health, I believe, by being out doors in all weathers. But I don't wish to go over the whole subject; I desire merely to speak of a few points omitted by others. One of these, and very important, is the early recognition of the tuberculous origin of indefinite attacks in young people and children. In many cases healed tuberculous lesions being found at autopsy, it is stated that there were no symptoms during life. It is possible that inquiry might elicit the fact that the patient, when a child, had had recurrent attacks with pronounced or vague chills. a sudden development of fever. and perhaps pectoral signs which were thought to be the symp toms of bronchitis or influenza or malaria or something else. I have seen many such patients, who will go free for months or years, when there will be a repetition of the same phenomena. They are not cases of influenza or malaria or typhoid fever. and while bronchitis or perhaps catarrhal pneumonia is manifest by physical signs, this is but a part of the morbid conplexus. I am inclined to believe that these are cases of tubereulosis chiefly localized in the bronchial glands, and my experience indicates that some patients recover entirely and some later develop pulmonary tuberculosis. Regarding the diagnostic value of temperature. I lay particular stress on the rise which occurs between noon and 2 p.m. Often a temperature course, seemingly normal at all other periods, shows a dis- 
tinct elevation during these hours. As a matter of convenience I select 1 p.m. for the first test. There is one exception; namely, patients who present an inverse temperature, i. e., higher in the morning than in the evening. The temperature of patients with tuberculosis is mostly affected by external surroundings. The heat of summer will sometimes send the temperature of such a one up one, two or three degrees.

In estimating the value of new methods of treatment reporting many recoveries, the element of time must be taken into consideration. Reports of recovery in six weeks may be thrown into the waste-basket; reports of patients remaining well six months need little attention; reports after one year or two years do not mean very much. I do not know just when to report cases of tuberculosis as well. I used to say four or five years was a sufficient time, but one patient reported well at four years died four years later of pulmonary tuberculosis. I have one patient now who has been well for seventeen yearsmy first case-treated by compressed air, iodoform, iron, rawmeat diet, etc. This I may report now to illustrate one line of treatment which has been successful in a certain proportion of cases.

Finally, I would ask members to read old books as well as new journals. Rush, in his classic on the treatment of consumption, calls attention to the value of rest and the value of regulated exercise in a way that impressed me greatly. He says: "I desire to call attention to the care with which exercise should be applied in cases of consumption in order that I unay in some measure atone for the evil done by neglect of these precautions in my early practice."

Beginning with the slightest exercise, conformable to the ability of the patients and the stage of the disease, he advises that it should be gradually increased until they could be kept out of doors on horse-back. The stages were slow carriage-riding, faster carriage-riding, walking, running, horseback. Sydenham, before this, had called attention to horseback exercise as one of the best means of treating phthisis; while Beddoes, more than a hundred years ago, gave the hygienic regimen which is now so enthusiastically exploited by those "who only heard it yesterday."

DR. S. A. KNopF, New York-I did not come here to speak, but simply to listen and learn. However, I gladly avail myself of the privilege to say a few words on the invitation of your honored Chairman. In listening to the many interesting papers on tuberculosis I have indeed learned much. The most important thing which the papers and discussions show is the advance we have made in phthisiotherapy, so that we no longer treat consumption, but the consumptive, and we no longer believe in a specific climate for pulmonary invalids. My time is too limited to discuss all the interesting points in the various papers presented here this afternoon.

To Dr. Freudenthal's experience with the sweatshop tailors as a class much exposed to consumption, let me add that $I$ have observed two other classes of laborers also very frequently attacked by this disease, namely, assorters of dirty linen in laundries and Italian rag-sorters. I have not seen any statistics to confirm my observations, but it would be interesting to know the real extent of the disease among these classes of laborers. That I may not be misunderstood, I wish to say that $I$ refer to the rag sorters who live and work often in the damp, dark, crowded basements of tenements, and not to the ragpickers, who work all day outdoors and are much less exposed to tuberculosis.

Concerning exercise and rest-cure, I would say that both are valuable in the treatment of the disease in question, but that neither should be carried to excess. To have a patient lie for from five to ten hours on his back on a reclining-chair, with almost no interruption, as is sometimes practiced in German sanatoria, even if out-of-doors, I consider dangerous to the patient, for it may produce a pulmonary hypostatic congestion. The rest-cure is most valuable when alternated with short walks and breathing exercises, providing the patient has little or no fever. A temperature of $100 \mathrm{~F}$. and over is an indication for quiet, and the less active exercise the patient gets the better. When the fever has become chronic gentle massage is well indicated, thus counteracting the disadvantages of a tooprolonged rest.

Dr. Mays' paper was certainly very interesting, but I fear we can not get the full value of his statistics as long as he does not tell us which of his patients had and which did not have the hygienic and dietetic treatment in addition to the nitrate of silver injections. We must admit that some patients' coughs improve and some get entirely well without any medicinal treatment. It may be interesting to recall in connection with this that Landouzy, of Paris, injects sterilized water into the supraclavicular region as cough remedy, and reports good success. My own favorite remedy for cough without expectoration is discipline. I tell the patient, in the language of my venerable teacher, Professor Dettweiler, that to cough in public simply because the throat tickles is impolite, like scratching the head in the presence of others when it itches; also that useless coughing only irritates the throat. At times I employ dry cupping to relieve cough and pleuritic pains. Of course, there are cases where the cough becomes distressing and where expectorants are necessary.

Before closing, may I come back to the cause of consumption among the toilers? Whatever we may do in the line of therapy or prevention by the sanatorium treatment, of which $I$ am glad to say such favorable mention has been made by Dr. Rochester, let me tell you that as long as the law will permit tenements to exist, or to be constructed, which, owing to the lack of air and light and want of cleanliness constitute veritable hotbeds of tuberculosis, so long will sanatoria and special hospitals serve only as recipients of the supply of tuberculous patients daily ereated anew.

Before you leave this meeting let me beseech you to do your duty as physicians and citizens. You have a right to demand from your municipal government that the poor shall be better housed and shall no longer constitute a danger to their fellowmen. You have a right to demand that the hopeless, poor consumptive shall be isolated in a special hospital and the curable treated in a sanatorium near by. There is hardly a region in the United States where the climate would not permit a consumptive to be cured by the hygienic and dietetic treatment under careful medical supervision. It is no longer necessary to send our patients thousands of miles away. In our combat against this bitter foe of mankind we must not forget that consumption must be treated as much in its social as in its medical aspect.

Dr. R. C. NEwTon, Montclair, N. J.-I wish to relate a case which has proved interesting to me, and I think supplements some of the remarks just made. About two months ago a young lady, of 19 or 20 years, was referred to me with the following history: She had suffered from loss of vigor and from depression of spirits for some months; during this period her menses had been entirely absent. She had lost flesh and had shown an afternoon temperature of 101 to $102 \mathrm{~F}$. The temperature had been taken at variable intervals. But $I$ have no doubt that she had experienced a daily rise during at least a considerable portion of the time mentioned. She had not suffered markedly from anorexia or constipation. Her elder sister hinted vaguely at some love affair, which might have affected her health.

When $I$ first saw her she was pallid, had some acne and complained of being listless and tired. Her family history was strongly tuberculous, so far as her grandparents, uncles and aunts were concerned. The history of her immediate family is very good. She complained of more or less dry cough every morning, but no expectoration. A careful swabbing of her throat produced a little mucus, which was examined in vain for tubercle bacilli. The blood was examined microscopically and showed some leucocytosis, the polymorphonuclear leucocytes being well marked. The red cells were comparatively healthy, showing only a few endoglobular changes. There were no malarial plasmodia. A careful auscultation and percussion of the chest seemed to reveal slight congestion at the right apex; so a tentative diagnosis of incipient phthisis pulmonalis was made. I referred the patient to Dr. James, of New York City, for further examination and for advice as to whether she 
should be sent to the Adirondack Sanatorium or not. Dr. James was disposed to regard the case as purely one of anemia and recommended large doses of tartrate of iron and potash, the patient to be carefully watched and her progress noted.

How this case may turn out is, of course, too early to assert. But there seems to be little doubt that a moderate diurnal fevex may arise in ehlorotic young girls from nutritional or metabolic irregularities and may subside without sequelæ, and very probably without treatment.

Dr. C. P. Ambler, Asheville, N. C.-Dr. Rochester is labor. ing under the impression that I am connected with a sanatorium in Asheville, and have read this paper as a report from such institution. Allow me to state that I have no connection with the sanatorium, and that these patients reported were not treated in a sanatorium. He probably has this impression from the fact that $I$ was formerly connected with an institution in Asheville, but my connection with that institution was severed four years ago. Dr. Rochester has also stated that I make it appear that patients do not recover under creosote treatment. I did not say that. I stated that "where patients recovered under serotherapy they were not so liable to relapse as those treated by creosote and other allied drugs."

Dr. Knopf, in discussing my paper, has implied that I claim the results obtained were due entirely to medication. I distinctly stated that medication occupied third place. First, comes the hygienic supervision of the patient; second, good climate; third, medication. If all three of these methods can not be applied in a case, then the best thing the patient can do is to drop his doctor first, climate next, but under every cireumstance hygienic supervision of the patient is absolutely necessary.

I am not here posing as a serum champion. I presented this report simply as a supplement to the report of the 106 cases presented last year, at which time my paper on sero-medication was read. I have shown that now, after the lapse of two years, 31 of the 106 cases were all back at their former employment.

Dr. Thomas J. Mays, Philadelphia-I think it is of great importanee that we look on a new therapeutic question with leniency, for under the most favorable circumstances it is difficult to establish the correctness of any theory, and nowhere does this obtain more firmly than in the field of therapeutics, where the factors on which the theory is founded are so incon. stant and variable. Some of the objections raised by Dr. Vaughan are that nitrate of silver may produce argyria, and be provocative of phthisis. I do not believe, however, that the small doses of $1 / 10$ or $1 / 8$ grain given once a week have the least perceptible general effect on the patient, and if my recollection serves me right, it appears that much larger doses of this drug are required to be given continually and for a long time before the symptoms of argyria are produced. Nitrate of silver is frequently given in daily grain doses for months in intestinal diseases without deleterious effect. That nitrate of silver may predispose to phthisis I believe, but the same may be said of lead, mereury, arsenic and other drugs. This is only true, however, when administered in large and toxic doses, and for long periods, as happens in the arts and manufactures. Indeed, I believe that anything which disintegrates, or diminishes the integrity of, the nervous system, as the above-named agents do in maximum doses, will predispose to pulmonary consumption. In small doses they stimulate, while in large doses they intoxicate.

Dr. Rochester asks me to define the meaning of patients getting practically well. This is a hard question to answer. Precisely, I believe that no tuberculous or phthisical patient will be entirely free and secure from the development of the disease if he lives a thousand years. The same may be said of many of us who carry inherited burden of this disease in our bodies and who, under prolonged physical or mental oppres. sion, show a proclivity to the disease by the symptoms of a light cough, loss of flesh, impairment of appetite, etc. Therefore, I believe that a person who has been subject to this disease and recovers is never free absolutely from a subsequent outbreak, although he may be said to be practically well, espe- cially if he is capable of performing work for six months, a year, or longer, provided he maintains his appetite, flesh, etc. The same is, however, also true of perhaps all chronic diseases.

Dr. Cohen referred to healed lesions of early tuberculosis usually occurring in children. I think it is true in many instances that children show a proclivity toward cure. I think they make quicker recovery than adults. I think in the "Medical and Surgical History of the War of the Rebellion" many cases of healed cavities and cicatrized phthisical lesions were noted in the lungs of soldiers who had died of other causes than phthisis.

Dr. A. F. LEMKe, Chicago-I have but a few words to say in closing. In reference to the remarks of Dr. Rochester, I would say that I think every one is aware of the fact that a great majority of cases which develop pneumothorax in con. nection with tuberculosis result fatally; I believe that I am perfectly safe in saying that 90 per cent. or more of these cases of pneumothorax result fatally. There are two reasons: 1. On account of the valve-like formation at the point of rupture, so much air is forced into the pleural cavity that the patient dies of shock. 2. A more or less virulent infection of the pleura. Dr. Rochester states that in his case there was no pus, but this does not indicate that there was no infection.

It seems to me that the only practical way of getting at the question of the treatment of tuberculosis-nut including prophylaxis-and the only rational way, is to consider how tuberculosis heals in a natural way. The great nujority of lesions of tuberculosis, particularly those occurring in the lungs, hea] by the process of cicatrization. In my synopsis, with which you are supplied, I have made a note regarding the statistics referring to the curability of tuberculosis. Every one is aware that Harris, of England, reported that 38 per cent. of individuals who died of causes other than tuberculosis showed healed tuberculous lesions in the lungs.

Fibrosis is the all-important factor in the healing of tuberculosis of the lungs. That compression will favor fibrosis can no longer be disputed. Furthermore, the danger from tubes culosis lies in the dissemination of the disease throughout the lungs. There are certain well-organized avenues by which this dissemination takes place, and these avenues are the air-chan nels, the lymph-vessels, and the blood-vessels. When compression takes place it oceludes the avenues of dissemination of the virus and limits the disease to the parts originally in fected. In that way the process of fibrosis circumscribes and permeates the original focus, which is transformed into a scar. and these scars are simply masses of fibrous tissue, or scars enclosing calcareous or caseous material. Our work, which has been carried on extensively for two years. has convinced me that pulmonary compression has an important place in the treatment of tuberculosis and that is based on unimpeachable. clinical and pathological evidence.

\section{ANGINA EPIGLOTTIDEA ANTERIOR REPORT OF THREE CASES.* \\ CLEMENT F. THEISEN, M.D.}

Instructor in Diseases of the Nose and Throat, Albany Medical College; Attending I aryngologist to St. Peter's. Child's Hospitals, and Troy Hospital. ALBANY, N. Y.

The name "angina epiglottidea anterior" was given to this interesting condition by Michel, in 1878. It is an inflammatory process involving the anterior surface of the epiglottis, as a rule confined to it, and accompanied by more or less edema, which is the characteristic feature of this affection. The larynx itself may be affected to a certain extent.

True angina epiglottidea anterior occurs quite often as a primary affection, and is a separate and distinct condition. This statement will, I think, be proved by

* Presented to the Section on Laryngology and Otology, at theFifty-first Annual Meeting of the American Medical Association. held at Atlantic City, N. J., June 5-8, 1900. 